\title{
On the Investigation of Awareness Level of Family Planning among Rural Dwellers in Nigeria (Principal Component Analysis Approach)
}

\author{
Femi Joshua Ayoola', Nureni Olawale Adeboye ${ }^{2}$, Kayode Balogun ${ }^{3}$ \\ ${ }^{1}$ Department of Statistics, University of Ibadan, Ibadan, Nigeria \\ ${ }^{2}$ Department of Mathematics \& Statistics, Federal Polytechnic, Ilaro, Nigeria \\ ${ }^{3}$ Federal School of Statistics, Ibadan, Nigeria \\ Email: ayoolafemi@yahoo.com, adeboye_olawale@yahoo.com,kaylbalogun@yahoo.com
}

How to cite this paper: Ayoola, F.J., Adeboye, N.O. and Balogun, K. (2017) On the Investigation of Awareness Level of Family Planning among Rural Dwellers in Nigeria (Principal Component Analysis Approach). Open Access Library Journal, 4: e3762.

https://doi.org/10.4236/oalib.1103762

Received: June 23, 2017

Accepted: August 7, 2017

Published: August 10, 2017

Copyright $\odot 2017$ by authors and Open Access Library Inc.

This work is licensed under the Creative Commons Attribution International License (CC BY 4.0).

http://creativecommons.org/licenses/by/4.0/

(c) † Open Access

\begin{abstract}
This study examined the awareness level and attitude of family planning among rural dwellers in the South western part of Nigeria and its consequences on population/economy of Nigeria. Data were gathered from 300 respondents who were randomly selected from Seriki rural communities of western Nigeria using proportional allocation of the stratified random sampling technique. The research considered to know the level of awareness between the traditional family planning methods and modern methods of contraception. The modern methods were found to be more significantly embraced than traditional family planning methods based on the analysis of the result obtained which showed that $175 \%$ preferred modern methods while $125 \%$ preferred traditional methods. The factors considered in examining these are educational background, economic factors, marital status, social factor, ethnicity and illiteracy level; the data collected based on these factors are analyzed using principal component analysis technique in order to determine the most prevalent factor that causes attitudinal problems. The results give rise to the Eigenvalues and Eigenvectors of the components, whereby the variance proportion for each is given as $0.4844,0.2391,0.1480,0.0597,0.0461$ and 0.0227 for economics, educational background, ethnicity, illiteracy, marital status and social status respectively, thereby qualifying the factors as the first PC, second PC, third PC, fourth PC, fifth PC and sixth PC respectively. Thus, economic factor which is the first $\mathrm{PC}$ is the factor that is predominantly responsible for the discovered low level of awareness and poor attitudinal behavior towards family planning.
\end{abstract}




\section{Subject Areas}

Mathematical Statistics

\section{Keywords}

Family Planning, Principal Component, Eigen Values and Vectors, Marital Status and Contraceptives

\section{Introduction}

Family planning implies the ability of individuals and couples to anticipate and attain their desired number of children by spacing and timing their births. It is achieved through the use of contraceptive methods and the treatment of involuntary fertility. The availability of family planning does more than enabling women and men to limit family size. It safeguards individual health and right and improves the quality of life of couples and their children.

Family planning has attracted attentions all over the world due to its relevance in decision making, population growth and development. Family planning is defined as birth spacing, preventing unwanted pregnancies or secure wanted pregnancy. [1] [2] defined family planning as the practice that helps individuals or couples to attain certain objectives such as avoiding unwanted pregnancies, bringing about wanted babies at the right time, regulating the interval between pregnancies, controlling the time at which birth occurs in relation to the ages of parents and determining the number of children in the family. Family planning is a means of reproductive health. In spite of the hue and cry in and outside Nigeria about family planning or birth control, many people are still confused about its meaning, the methods involved, the advantages and disadvantages and the factors hindering its wide application in Nigeria, especially among the rural communities [3]. Women's education enhances their capability and also their reproductive rights to decide freely and responsibly the number, spacing and timing of their children and to have other necessary information regarding reproductive rights. Studies have shown that education is a determinant of awareness of family planning practices in Nigeria, for instance [4] investigated the extent of family planning, the methods and contraceptive devices in use and the influence of education on family planning among couples in Nkanu Local Government Area of Enugu State. The findings revealed that educational background of the couples significantly influenced the choice of family planning in the community.

[5] found out that women's education is in line with lower fertility which constitutes management of reproductive resources. Maternal education has once been linked with reduction of child mortality among rural dwellers. Recent studies have also shown that religion is a good determinant of family planning practices. [6] identified some factors such as cultural background, and religious 
beliefs which place the women at disadvantaged position in reproductive health issues. According to [3], Catholic Church is rigid in their views of family planning. Catholics hold the view that the application of artificial method is wrong and should not be allowed. The Catholic Church is said to be comfortable with the use of Billings's ovulation method which is rather natural. [7] conducted a study on the relationship between religious beliefs and family planning practices of married women in zone 5 barracks of the Nigeria police, comprising Edo, Delta, and Bayelsa state commands. The findings of the study revealed that attitudinal factor such as the strong religious desire for more children prevented women in these barracks from using family planning. Also noted were the insufficient knowledge on contraceptives methods, their fears and anxieties, rumor of others using contraceptives getting deleterious effect and poor delivery of health services [8]. Traditional methods such as coitus interruptus is described in Bible, periodic abstinence was used in ancient India and the precursor to the condom was used by the Egyptians back in 1350 BC [9]. Of recent, [10] conducted a similar research in among rural dwellers in Pakistan and findings reveal that the majority knew about some modern contraceptive methods, but the overall contraceptive use was very low. Knowledge and use of any contraceptive method were particularly low. Reasons for not using family planning and modern contraception included incomplete family size, negative perceptions, in-laws' disapproval, religious concerns, side-effects, and lack of access to quality services.

The practices of modern contraceptives method offer many advantages compared to traditional approaches, in health and economy of the couples in the country. Family planning programs that stimulate modern approaches, policies and methods have become increasingly important in the last decades as a result of the social-economic problems influencing rapid population growth, as well as public health problems, especially control of sexually transmitted diseases (STDs) such as AIDS [11]. The unwelcomed attitude of most rural dwellers to modern family methods has constitutes a continuous growth in African population size keeping it almost permanently underdeveloped, There is general believe that economic stagnation is often linked with over population and poor investment in health services and with Nigeria's population currently put at over 140 million people compared with Gross Domestic Product (GDP) that is not too encouraging and inflation still sky-rocketing, there is the fear that future living standards may substantially depreciate [12]. In recent years, population growth has begun to be discussed in terms of its effect on global stability. Some of the supporters of this view have suggested that in post-cold war order, the growth of population has the potential to undermine the global stability. According to [13], understanding of family planning scenario among different societies and communities, which by and large reside in urban slum and rural areas, might prove useful in increasing family planning acceptance by them and decreasing population growth. Within the context of above literatures, it has therefore becomes imperative to carry out this study in Seriki community; a rural community lo- 
cated in Ogun state, western region of Nigeria. The factors considered in examining this scenario are educational background, economic factors, marital status, social factor, ethnicity and illiteracy level; Principal component analysis technique shall be employed to fit model for each of the factor in order to determine the most prevalent among them that cause attitudinal problems to family planning among rural dwellers.

\subsection{Research Design and Methodology}

The study area of this research is Seriki community in Ogun State and is accessible by land. The community comprises of different ethnic groups namely Yoruba's, Igbo, Hausa, Calabar, Isoko, Ijaws, just to mention but few. The Yoruba's are considered to be the more than any other tribes in the city, because it is located at the western part of Nigeria. According to the unpublished census figure of 2006, its population size was estimated at a total of 2075. The community was divided into nine (9) strata and a sample size of 335 estimated through Taro Yanmeni's formula was randomly selected among focus group of age $15-30^{+}$ comprises of single ladies, married couple and the divorced people using proportional allocation of Stratified random sampling technique.

Designed questionnaire was examined on the selected sample size under three (3) different categories. The instrument sought to solicit responses on area of residence, age at marriage, and highest educational qualification, duration or age of marriage, and number of children owned. The second category of the questionnaire covers the factors that encourage large families and their general perception on family planning. The major factors considered here are educational background, economic factors, marital status, social factor, ethnicity and illiteracy level. The third part purely seeks information on family planning acceptance in both modern and traditional way. At the end of the survey, a cronbach's alpha validity rest was run on a sample of 100 respondents for reliability measures and the survey was found to be $81.2 \%$ reliable. This analysis was based on responses from the last two categories being the categories that cover the research questions.

\subsection{Data Analysis}

The analytical technique adopted for this research is a Multivariate analysis technique known as Principal Component Analysis.

It is a statistical procedure that uses an orthogonal transformation to convert a set of observations of possibly correlated variables into a set of values of linearly uncorrelated variables called principal components. This transformation is defined in such a way that the first principal component has the largest possible variance (that is, accounts for as much of the variability in the data as possible), and each succeeding component in turn has the highest variance possible under the constraint that it is orthogonal to the preceding components. The principal components are orthogonal because they are the Eigen vectors of the covariance 
matrix, which is symmetric.

If the variables $Y_{1}, Y_{2}, \cdots, Y_{p}$ in $\mathrm{Y}$ are correlated, the ellipsoidal swarm of point is not oriented parallel to any of the axis. The axes can be rotated by multiplying each $y_{i}$ by an orthogonal matrix $\boldsymbol{A}$ and thus obtain

$$
Z_{i}=A Y_{i}
$$

Since $\boldsymbol{A}$ is an orthogonal, $\boldsymbol{A}^{\prime} \boldsymbol{A}=\boldsymbol{I}$ and the distance to the origin is unchanged. Thus we want to sample covariance matrix of $\boldsymbol{Z S Z}=\boldsymbol{A S A ^ { \prime }}$ to be diagonal.

$$
\boldsymbol{Z S} \boldsymbol{Z}=\boldsymbol{A} \boldsymbol{S} \boldsymbol{A}^{\prime}=\left\{\begin{array}{ccc}
S^{2} z_{1} & 0 & 0 \\
0 & S^{2} z_{1} & 0 \\
0 & 0 & S^{2} z_{1}
\end{array}\right\}
$$

Thus the orthogonal matrix $A$ that diagonalizes $S$ is the transpose of the matrix $C$.

$$
\boldsymbol{A}=\boldsymbol{C}^{I}=\left[\begin{array}{l}
a_{1} \\
a_{2} \\
a_{p}
\end{array}\right]
$$

\subsection{Eigenvalues and Eigenvectors}

For every square matrix $A$, a scalar $\lambda$ and a nonzero vector $\boldsymbol{x}$ can be found such that $\boldsymbol{A x}=\lambda \boldsymbol{x}$. It should be known that $\lambda$ is called an eigenvalue of $\boldsymbol{A}$, and $\boldsymbol{x}$ is an eigenvector of $\boldsymbol{A}$ corresponding to $\lambda$. To find $\lambda$ and $\mathbf{x}$, we write the equation as as $(\boldsymbol{A}-\lambda \boldsymbol{I}) \boldsymbol{x}=\mathbf{0}$.

If $|\boldsymbol{A}-\lambda \boldsymbol{I}|=0$, then $(\boldsymbol{A}-\lambda \boldsymbol{I})$ has an inverse and $\boldsymbol{x}=\mathbf{0}$ is the only solution. Hence, in order to obtain nontrivial solutions, we set $|\boldsymbol{A}-\lambda \boldsymbol{I}|=0$ to find values of $\lambda$ that can be used to find corresponding values of $\boldsymbol{x}$. Thus, in $(\boldsymbol{A}-\lambda \boldsymbol{I}) \boldsymbol{x}=\mathbf{0}$, the matrix $\boldsymbol{A}-\lambda \boldsymbol{I}$ must be singular in order to find a solution vector $\boldsymbol{x}$ that is not $\mathbf{0 .}$

Suppose we have a $3 \times 3$ matrix $A$ with eigenvectors $X_{1}, X_{2}, X_{3}$, and eigenvalues $\lambda_{1}, \lambda_{2}, \lambda_{3}$ so that

$$
A x_{1}=l_{1} x_{1}, A x_{2}=l_{2} x_{2}, A x_{3}=l_{3} x_{3}
$$

thus,

$$
\boldsymbol{A}\left[\begin{array}{lll}
\boldsymbol{X}_{1} & \boldsymbol{X}_{2} & \boldsymbol{X}_{3}
\end{array}\right]=\left[\begin{array}{lll}
\boldsymbol{X}_{1} & \boldsymbol{X}_{2} & \boldsymbol{X}_{3}
\end{array}\right]\left[\begin{array}{ccc}
\lambda_{1} & 0 & 0 \\
0 & \lambda_{2} & 0 \\
0 & 0 & \lambda_{3}
\end{array}\right]
$$

The eigenvalues will then be used to compute the variance of the principal components and we can speak of the proportion of variance explained by the first $\mathrm{K}$ component.

\subsection{Eigenvectors of Covariance Matrix}

We will derive our first algebraic solution to PCA using linear algebra. This solution is based on an important property of eigenvector decomposition. The 
sample correlation between the th and $k$ th variables is defined as Covariances $\boldsymbol{X}^{\mathrm{T}} \boldsymbol{X}$ itself can be recognized as proportional to the empirical sample covariance matrix of the dataset $X$.

\section{Result and Discussion}

\subsection{Results}

See Figures 1-2, Tables 1-4.

\subsection{Discussion}

In Table 1, correlations among the causative factors were considered. The most prevalent dependence was exhibited between Educational background and Economic factor with a high positive correlation of 0.85 and that shows at what level the correlation value will be of importance. Some of the factors equally exhibited negative correlation with one another while others exhibited weak positive correlation.

According to Table 2, the main component variables are defined as linear combinations of the original variables. The model for the equation above are:

$$
\begin{aligned}
\mathrm{PC} 1= & 0.525305(\text { E.F })+0.498518(\text { E.D })-0.295534(\text { ethnicity }) \\
& -0.463585(\text { illiteracy })+0.339941(\text { M.S })-0.240255(\text { S.F }) .
\end{aligned}
$$

\begin{tabular}{|c|c|c|c|c|c|c|}
\hline & E.F & E.B & ETHNICITY & ILLITERACY & $\begin{array}{c}\text { MARRIAGE_ } \\
\text { STATUS }\end{array}$ & $\begin{array}{l}\text { SOCIAL } \\
\text { FACTOR }\end{array}$ \\
\hline $\begin{array}{c}\text { ECONOMIC_ } \\
\text { FACTOR }\end{array}$ & 1.000000 & & & & & \\
\hline E.B & 0.853992 & 1.000000 & & & & \\
\hline ETHNICITY & -0.260151 & -0.174099 & 1.000000 & & & \\
\hline ILLITERACY & -0.688533 & -0.683219 & 0.134808 & 1.000000 & & \\
\hline $\begin{array}{c}\text { MARRIAGE_ } \\
\text { STATUS }\end{array}$ & 0.353807 & 0.234607 & -0.719295 & -0.217871 & 1.000000 & \\
\hline $\begin{array}{c}\text { SOCIAL_FAC } \\
\text { TOR }\end{array}$ & -0.247535 & -0.224509 & 0.137374 & 0.281727 & -0.132131 & 1.000000 \\
\hline
\end{tabular}

Table 1. Ordinary correlations.

Table 2. Eigenvectors.

\begin{tabular}{ccccccc}
\hline Variable & PC 1 & PC 2 & PC 3 & PC 4 & PC 5 & PC 6 \\
\hline E.F & 0.525305 & 0.192413 & 0.174055 & 0.349704 & 0.099909 & -0.724197 \\
E.B & 0.498518 & 0.289330 & 0.192530 & 0.413398 & -0.079352 & 0.673428 \\
ETHNICITY & -0.295534 & 0.653014 & -0.005069 & -0.029402 & 0.695535 & 0.039670 \\
ILLITERACY & -0.463585 & -0.295967 & -0.043416 & 0.825845 & 0.116089 & -0.010534 \\
M.S & 0.339941 & -0.601188 & 0.065349 & -0.117261 & 0.696298 & 0.141992 \\
S.F & -0.240255 & -0.061762 & 0.962526 & -0.100871 & -0.040569 & -0.013651 \\
\hline
\end{tabular}




$$
\begin{aligned}
\text { PC2 }= & 0.192413(\text { E.F })+0.289330(\text { E.B })+0.653014(\text { ethnicity }) \\
& -0.295967(\text { illiteracy })-0.601188(\text { M.S })-0.061762(\text { S.F }) . \\
\text { PC3 }= & 0.174055(\text { E.F })+0.192530(\text { E.B })-0.005069(\text { ethnicity }) \\
& -0.043416(\text { illiteracy })+0.065349(\text { M.S })+0.962526(\text { S.F }) \\
\text { PC4 }= & 0.349704(\text { E.F })+0.413398(\text { E.B })-0.029402(\text { ethnicity }) \\
& +0.825845(\text { illiteracy })-0.117261(\text { M.S })-0.100871(\text { S.F }) . \\
\text { PC5 }= & 0.099909(\text { E.F })-0.079352(\text { E.B })+0.695535(\text { ethnicity }) \\
& +0.116089(\text { illiteracy })+0.696298(\text { M.S })-0.040569(\text { S.F }) . \\
\text { PC6 }= & -0.724197(\text { E.F })+0.673428(\text { E.B })+0.039670(\text { ethnicity }) \\
& -0.010534(\text { illetracy })+0.141992(\text { M.S })-0.013651(\text { S.F }) .
\end{aligned}
$$

In line with Equations (5) to (10), PC1 to PC6 represent the six stated factors respectively and the first principal component is positively correlated with three out of six of the original variables while others experienced negative correlation. Thus, the first principal component increases with the increase in economic factor, educational background and marriage status and this suggest that these three criteria vary together. If one increases, then the remaining two also increase. This component can be viewed as a measure of the quality of economic factor, educational background and marriage status. Furthermore, we see that the first principal component correlate moderately with the economic factor. In fact, we could state that based on the correlation of 0.525 that this principal component is a primary measure of the economic factor. It would follow that communities with high values would tend to have a lot of economic factor available around them in terms of economic status, type of family and this shows that economic factor will affect family planning in the community.

The second principal component also increases with ethnicity, educational background and economic factor. This component can be viewed as a measure of the degree of ethnicity in the community with a positive value of 0.65 . Thus, this principal component is the primary measure of ethnicity which indicates that ethnicity also affects the attitudes to family planning in the community.

The third principal component is highly correlated with social factor with value of 0.962 follow by educational background, economic factor and marriage status. It implies that this component is the primary measure of social factor in the community. Thus, a degraded level of social factor within the community has had serious effect on their family planning attitudes.

The fourth principal component also strongly correlated with illiteracy level in the community with a value of 0.825 , follow by educational background and economic factor. This component is the primary measure of illiteracy in the community, which indicates that there is high level of illiteracy in the community which is also affecting the family planning attitudes in the area.

The fifth principal component is the primary measure of marital status with a value of 0.696 . This implies that marriage status of the focus group have strongly 
impacted on the community's attitudes to family planning in the area.

The sixth principal component is the primary measure of educational background with value of 0.67 follow by marriage status, which indicate that educational background contributes a lot to the attitudes of family planning in the area.

Table 3 shows that Economic factor has the highest variance proportion of 0.484 follows by Educational background with a variance proportion of 0.239 and it thus appears that the poor attitudes of the community dwellers are mostly affected by the first two principal components, and together they explained $72.35 \%$ of the total variation in the acceptability of family planning attitudes under study. This leads us to the conclusion that a two factor solution will probably be sufficient with the eigenvalues of 2.906611, difference of 1.472286, variance of 0.4844 and 1.434 , difference of 0.5463 , variance of 0.2391 . The remaining other four components jointly explained $27.65 \%$ of the attitudes.

"Figure 1 Scree plot is a principal component analysis chart to determine how many important components are present in the data, the scree graph plot the Eigen values against the component number. It can be easily observed that only the first two components crossed above the cut-off line, meaning that the remaining components account for smaller amounts of the total variance. Generally we are interested in keeping only those principal components with Eigen values greater than one. However, two factors were extracted based on significance of Kaiser Criterion (Kaiser, 1960).

Table 4 shows a section displaying the estimates of the unrotated orthogonal loading, communalities and uniqueness estimates obtained from the estimates. we see that veliger MAP method has retained two factors, labeled F1 and F2 a brief examination of the unrotated loadings indicate that economic factor and educational background load on the first factor while ethnicity load on the second factor. To the right of the loadings are communality and uniqueness which apportion the diagonals of the correlation matrix into common (explained) and individual (unexplained) components therefore, the communalities explained what each variable can be accounted for with their weight (unique-

Table 3. Sum of the variance proportion.

\begin{tabular}{|c|c|c|c|c|c|}
\hline \multicolumn{6}{|c|}{ Eigenvalues: $($ Sum $=6$, Average $=1)$} \\
\hline & & & & Cumulative & Cumulative \\
\hline Number & Value & Difference & Proportion & Value & Proportion \\
\hline 1 & 2.906611 & 1.472286 & 0.4844 & 2.906611 & 0.4844 \\
\hline 2 & 1.434325 & 0.546397 & 0.2391 & 4.340936 & 0.7235 \\
\hline 3 & 0.887928 & 0.529765 & 0.1480 & 5.228865 & 0.8715 \\
\hline 4 & 0.358163 & 0.081266 & 0.0597 & 5.587028 & 0.9312 \\
\hline 5 & 0.276897 & 0.140822 & 0.0461 & 5.863925 & 0.9773 \\
\hline 6 & 0.136075 & --- & 0.0227 & 6.000000 & 1.0000 \\
\hline
\end{tabular}


Table 4. Estimate of the Orthogonal.

\begin{tabular}{|c|c|c|c|c|c|}
\hline \multicolumn{6}{|c|}{ Unrotated Loadings } \\
\hline & $\mathrm{F} 1$ & F2 & Communality & Uniqueness & \\
\hline ECONOMIC_FACTOR & 0.888934 & 0.188602 & 0.825774 & 0.174226 & \\
\hline E.D & 0.840691 & 0.301768 & 0.797825 & 0.202175 & \\
\hline ETHNICITY & -0.436040 & 0.651089 & 0.614048 & 0.385952 & \\
\hline ILLITERACY & -0.711991 & -0.246761 & 0.567822 & 0.432178 & \\
\hline MARRIAGE_STATUS & 0.511711 & -0.620111 & 0.646385 & 0.353615 & \\
\hline SOCIAL_FACTOR & -0.300303 & -0.013913 & 0.090376 & 0.909624 & \\
\hline Factor & Variance & Cumulative & Difference & Proportion & Cumulative \\
\hline F1 & 2.546057 & 2.546057 & 1.549884 & 0.718772 & 0.718772 \\
\hline $\mathrm{F} 2$ & 0.996173 & 3.542231 & --- & 0.281228 & 1.000000 \\
\hline Total & 3.542231 & 3.542231 & & 1.000000 & \\
\hline
\end{tabular}

Observed Matrix Scree Plot

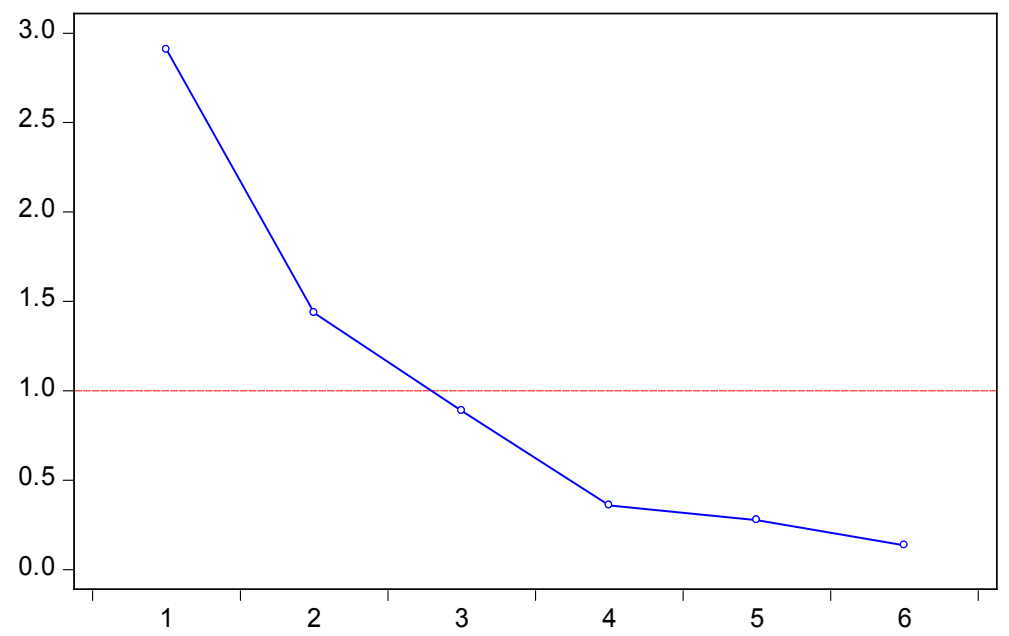

Figure 1. Observed matrix Scree plot.

ness). Thus, all the variables (factors) considered in this research are correlated since the ellipsoidal swarm of point is not oriented parallel to any of the axis as exhibited in Figure 2.

\section{Conclusion/Recommendation}

This research provides insights into the local contexts related to family planning knowledge, attitudes, perceptions, and practices and also highlights the need for contraceptives, both modern and traditional methods. In the wake of changing attitudes towards family planning and desired family size among rural dwellers, more women and couples will be seeking family planning services. Addressing obstacles such as access, affordability, and availability will help meet these needs and ensure that women and couples can meet their childbearing and reproductive 


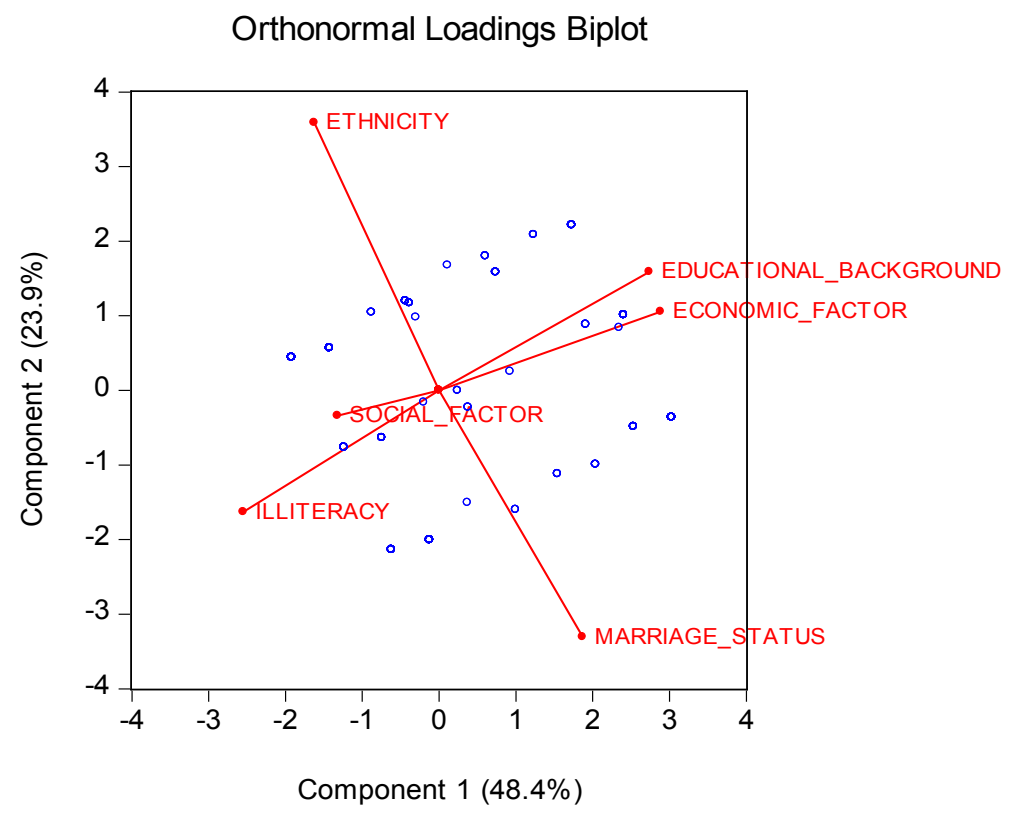

Figure 2. Orthogonal loadings.

health goals. In addition, a very low perceived need for contraception was found amongst the respondents wishing to bear more children. The result shows that the most important factors that affect people awareness are economic factor and educational background and they jointly have the highest variance proportion and the highest Eigenvalue which is greater than 1.

In view of the above, the following recommendations were however made:

1. The government should provide social economic factors that would increase the knowledge of education among the people which will improve their level of understanding of family planning.

2. In Nigeria, the bulk of the population lives in the rural areas. The government should therefore emphasize modern methods of family planning to complement the traditional methods, provide adequate fund for family planning officials to enable them procure the necessary devices and reach the rural dwellers.

3. Due to the fact that economic factors in the country are very poor, it is advisable for the people to reduce their child bearing in order to reduce the population of the country so that the provision of government amenities will be sufficient enough for community.

The study also recommends strong need for involving men in healthcare programs designed to improve women's and newborns' health as they mostly influence decision-making at the household level and this will also result in active male participation and community ownership. For Young, especially the first time, fathers need support and empowerment. Encouraging communication between wife and husband about family planning and birth spacing should also be part of such campaigns to promote mutual decision-making between wife and husband and make husbands responsible partners in family planning/birth 
spacing decisions and ease the burden of decision-making on women.

\section{References}

[1] WHO (2007) Taking Stock of WHO's Work in Crises in Uganda Health Action in Crisis (HAC).

[2] Beekle, A. and McCabe, C. (2006) Awareness and Determinants of Family Planning Practice in Jimna, Ethiopia. Journal of International Council of Nurses, 53, 269-276.

[3] Iffih, B. and Ezeah, P. (2004) Sociology of Family. John Jacob Classic Publishers Limited, Enugu.

[4] Anyanwu, J.I., Ezegbe, B.N. and Eskay, M. (2013) Family Planning in Nigeria: A Myth or Reality? Implications for Education. Journal of Education and Practice, 4, No. 15. http://www.iiste.org/

[5] WHO (2013) Family Planning. http://www.who.int/topics/family_planning/en/

[6] UNFPA (2013) Ensuring That Every Pregnancy Is Wanted. http://www.unfpa.org/rh/planning.htm

[7] Igbudu, U., Okoedions, S., Peremene, E. and Eghafona, K. (2011) Sociology of Family. John Jacob Classic Publishers Limited, Enugu.

[8] Bandura, A. (1986) Social Foundations of Thought and Action: A Social Cognitive Theory. Prentice Hall, Englewood Cliifs, NJ.

[9] Odimegwu, C.O. (1999) Family Planning Attitudes and Use in Nigeria: A Factor Analysis. International Family Planning Perspectives, 25, 86-91. https://doi.org/10.2307/2991946

[10] Ghulam, M., Syed, K.A., Waqas, H., Safdar, A., Mohammed, I., Wajahat, A., Aftab, A. and Eric, M. (2015) Family Planning Knowledge, Attitudes, and Practices among Married Men and Women in Rural Areas of Pakistan: Findings from a Qualitative Need Assessment Study. International Journal of Reproductive Medicine of Reproductive Medicine, 2015, Article ID: 190520.

[11] Ayoola, F.J. and Oshodi, O.C. (2013) On the Comparative Analysis of Determinant Factors on the Use of Condom among Nigerian Youths. Global Journal of Medical Research, 13, 1-7. https://globaljournals.org/GJMR

[12] Olatayo, T.O. and Adeboye, N.O. (2013) Predicting Population Growth through Births and Deaths Rate in Nigeria. Mathematical Theory and Modelling, 3, No. 1. http://www.iiste.org/

[13] Sharma, V., Mohan, U., Das, V. and Awasthi, S. (2012) Social Demographic Determinants and Knowledge, Attitude Practice: Survey of Family Planning. Journal of Family Medicine and Primary Care, 1, 43-47. https://doi.org/10.4103/2249-4863.94451 
Submit or recommend next manuscript to OALib Journal and we will provide best service for you:

- Publication frequency: Monthly

- 9 subject areas of science, technology and medicine

- Fair and rigorous peer-review system

- Fast publication process

- Article promotion in various social networking sites (LinkedIn, Facebook, Twitter, etc.)

- Maximum dissemination of your research work

Submit Your Paper Online: Click Here to Submit

Or Contact service@oalib.com 